\title{
Letramento Crítico e o Ensino de Língua Estrangeira na Escola Pública: Brechas e Possibilidades
}

Critical literacy and foreign language teaching in public schools: gaps and possibilities

João Paulo Xavier, Mestre em Linguística Aplicada, UFMG,xavierebedran@gmail.com

\section{Resumo}

O presente trabalho busca apresentar algumas reflexões feitas a partir das perspectivas metodológicas do Letramento Visual Crítico que objetiva auxiliar os professores e alunos a analisar, interpretar e se apropriar do conteúdo imagético, conduzindo a partir dele discussões críticas cujo objetivo seja a prática de um letramento visual crítico que empodere os alunos e amplie as suas possibilidades de aprendizagem.

Palavras Chave: imagem, livro-didático, criticidade

\section{Abstract}

This paper reflects on methodological perspectives for critical visual literacy, which can help teachers and students to scrutinize closely, interpret and take ownership of the content of images. This would lead them to critical discussions where the ultimate objective is to establish a practice of critical visual literacy that empowers students and expands their learning opportunities.

Keywords: image, textbook, criticality 


\section{Educação crítica}

$\mathrm{Na}$ atual sociedade globalizada e digitalizada, ser letrado, ou seja, ter domínio apenas sobre práticas de leitura e escrita já não é suficiente. O cidadão, hoje, precisa dominar várias outras habilidades para não apenas usufruir dos benefícios da vida moderna, mas também participar ativamente da comunidade na qual está inserido, fazendo intervenções construtivas e contribuindo de maneira ativa para o avanço da mesma. Por esse viés, o conceito de cidadania envolve a tomada de decisões políticas e criticamente (in)formadas por parte de sujeitos ativos, localizados historicamente (Monte Mor, 2009).

Segundo Monte-Mór (2014), o termo 'crítico' pode ser postulado de duas maneiras distintas, baseadas em Barthes (1999) e Gikandi (2005). A primeira a partir do uso do termo 'criticism' - em um sentido acadêmico, seria resultado da escolaridade -; e um segundo seria o termo 'critique', - em um sentido ideológico, ou seja, a capacidade crítica do sujeito não se atrelar aos níveis de escolarização a qual foi submetido, indicando assim a visão de que há pensadores críticos e pensadores comuns.

Ferraz, ao explorar esses conceitos, aponta três significados para o termo 'crítico' a partir de critique: na qualidade de construção de sentidos (Morin, 1998, 2000; Lankshear \& Knobel, 2003; Gee, 1997); Monte-Mór, 2008); o crítico como forma de não se confiar em uma interpretação dada, em que Monte-Mór baseia-se em Ricouer; e, finalmente, crítico enquanto ruptura, quebra de paradigmas (FERRAZ, 2014).

No tocante ao ensino de Línguas Estrangeiras, a partir dessas definições, percebemos que ser crítico implica ir além do status quo, a desconstruir o "olhar treinado" (DUBOC; FERRAZ, 2011, p. 24). Nesse sentido, Duboc e Ferraz (Ibid.) postulam que Monte-Mór (2009, 2010, 2011) vem sinalizando a relevância do trabalho de letramento crítico como uma prática de leitura comprometida com a expansão de perspectivas do aluno. Tal expansão consiste no exercício de construção de sentidos nas dimensões individual, comunitária e global, de forma a relacioná-las e, sobretudo, compreendê-las em suas semelhanças e diferenças ( $p$. 22, 23).

Partindo dessas reflexões, penso que uma educação crítica empenha-se nessa "expansão de perspectivas". Baseia-se no fato de que nenhum texto é neutro, de que a educação deve ser social, cultural e ideologicamente orientada.

\section{A formação de professores e a educação crítica}

Segundo Hawkins (2011), a literatura que trata da formação do professor de línguas privilegia assuntos pertinentes à língua e à pedagogia, em detrimento do impacto de questões de cunho sociocultural na linguagem, no letramento e na aprendizagem. Corroborando as ideas de Pennycook (2010), Hawkins (2011) aponta 
que tal fato deriva parcialmente das maneiras através das quais o próprio processo de ensino/aprendizagem tem sido historicamente abordado.

\begin{abstract}
Movendo-se de uma visão de língua como conjunto de palavras e estruturas governadas por princípios particulares armazenados na mente (uma abordagem psicolinguística) para uma visão de língua como ferramenta para criação de sentido (uma abordagem comunicativa), para uma visão de criação de sentido como situado em encontros sociais específicos que acontecem em lugares específicos, em momentos específicos, entre pessoas específicas (uma abordagem sociocultural), e, por último, para uma visão de uso de língua situada que é modelada pelas forças e ideologias políticas, culturais e sociais que servem para empoderar algumas pessoas e marginalizar outras (uma abordagem crítica) (HAWKINGS, 2011, p. 2).
\end{abstract}

O fato de que a maioria dos professores de línguas estrangeiras nunca passou por experiências de aprendizagem que se baseassem em uma educação crítica- e nem foram preparados para isso, encabeça a dificuldade dos mesmos em incluir estratégias metodológicas críticas para o ensino de LE. Penso que muitas das nossas escolas regulares no Brasil encontram-se ainda no que Hawkins chamou de "abordagem psicolinguística". De semelhante modo, a maioria dos cursos livres no Brasil, salvo algumas exceções que utilizam abordagem comunicativa. Note que o letramento crítico encontra-se dois estágios adiante.

Penso que a necessidade de mudança (impressa pela globalização, avanços tecnológicos etc.) em si mesma trará a urgência de uma prática nova - que, então, poderá tornar-se vigente $\mathrm{e}$, portanto mais familiar para aqueles que ainda se encontram limitados a praticas passadas que já sofreram alterações e melhorias. A prática docente deve ser propositada, ou seja, os professores precisam ter consciência do que fazem, pois somente assim, poderão levar seus alunos a compreender muito além de conceitos estruturais da língua ensinada, mas principalmente o que pode ser feito com esse conhecimento e como o mesmo é (trans)formador.

Van Mannen (1977) estabelece relações entre o conhecimento teórico gerado pela pesquisa educacional e o desenvolvimento curricular, as políticas educacionais e a prática escolar. O autor pontua três níveis distintos de ação: o primeiro nível, associado à noção de eficiência, apresentando uma prática mais preocupada com os meios do que com o fim (aprendizagem); o segundo é o nível da prática interpretativa, que analisa o significado das experiências, percepções individuais e culturais, buscando orientação para a ação pedagógica que justifica e legitima as práticas comuns; o terceiro nível se dá por meio de experiências mediadas por igualdade e justiça social, promovendo condições sociais e interpessoais para a aprendizagem reflexiva e emancipatória. Os níveis de ação estão ligados, respectivamente, aos "ways of knowing": 1) ciência empírico-analítica; 2) 
fenomenologia-hermenêutica; e 3) perspectiva crítica - sendo a fenomenologia da prática a área de atuação do autor.

Torna-se fundamental pensar na validade da práxis de um educador que busca, além de ensinar a língua, alargar o horizonte das possibilidades de seus educandos. Para tanto, torna-se imperativo esse conhecimento, diferenciação e reflexão sobre o que é uma Educação Crítica, Multiletramentos, Letramento Crítico, Letramento Visual Crítico.

Com o intuito de entender como essa relação se estabelece e os caminhos pelos quais um professor precisa percorrer a fim de ir além dos aspectos estruturais e gramaticais, faz-se imperativo compreender as OCEM (BRASIL, 2006), conceitos como "Educação Crítica", teorias como o Letramento Crítico (LC), para que vislumbremos questões culturais, políticas, ideológicas, identitárias e as relações de poder, dentre outras, que circundam as linguagens e as práticas sociais, tudo isso sem perder o escopo e o foco nos objetivos educacionais propostos pelo ensino e aprendizagem da língua inglesa.

A educação escolar caracteriza-se, dentre outras, pela mediação didática e pedagógica que se estabelece entre conhecimentos práticos e teóricos. Dessa forma, seus procedimentos e conteúdos devem adequar-se tanto às exigências da sociedade, à situação específica de cada escola, quanto ao desenvolvimento dos alunos frente aos diferentes desafios acadêmicos aos quais estão submetidos enquanto trilham uma jornada em busca da apropriação desses saberes. Nesse contexto, o livro didático (LD) adquire uma importância basilar, como um poderoso instrumento para reflexão e desenvolvimento das tarefas escolares, assim, como, para a formação crítica de cada aluno, atendendo a uma dupla exigência: de um lado, os procedimentos, as informações e os conceitos teóricos propostos nos manuais; do outro, a adequação desses às práticas docentes a que estão destinados (Tilio, 2008; Menezes, 2009; Holden, 2002 e Tortato, 2010;

Kumaravadivelu (2003; 2006), ao teorizar sobre 'a condição pós-método' explica que os contextos locais de ensino e aprendizado, a formação do professor, a aplicação de suas teorias profissionais pessoais em sua prática docente e o entendimento de que qualquer prática pedagógica também fazem parte das relações de poder, reforçam e justificam juntamente com as teorias do Letramento Crítico e as Orientações Curriculares do Ensino Médio as exigências encontradas na regulamentação dos livros didáticos no Brasil.

\section{Letramento visual crítico}

Ferraz (2014) aponta que com o advento das novas tecnologias, é preciso problematizá-las, discutindo como estas podem influenciar e serem influenciadas pelo modo como nos comunicamos e nos relacionamos. Enquanto educadores, precisamos estar atentos aos papeis atribuídos à fluência na Língua Inglesa, uma vez que vivemos em uma sociedade cada vez mais globalizada, por tanto se faz 
necessário reconhecermos a importância dos discursos globalizantes para o papel da língua inglesa nos dias atuais e a necessidade de inclusão, mas também de discussão, dessas tecnologias em nossas salas de aula. Desse modo, o Letramento Visual, para Ferraz (2014) é um importante campo de estudo dentro das novas demandas que enfrentamos como educadores, por ser

um campo de estudo que problematiza o estudo das imagens (estáticas, em movimento e mistas), a fim de: investigar a sua importância em todos os campos, questionar a ideia de representação, repensar as imagens como processos de produção de significados, ampliar perspectivas, interpretações e conhecimento. (FERRAZ, 2014, p. 21, minha tradução)

De acordo com Ferraz (2014), o Letramento Visual (LV) seria, portanto, como um subcampo dos novos letramentos e do multiletramento, pois aborda a imagem em suas múltiplas formas e considera, assim, a multimodalidade e o uso de diferentes mídias e tecnologias no processo de significação. Sabe-se que o significado é multimodal e os aspectos visuais passam a ser considerados. Ademais, o Letramento Visual pode-se inserir na perspectiva de Letramento Crítico por questionar o papel das imagens em nosso cotidiano e tratá-las como uma construção da realidade e não apenas uma representação imagética como postula Joly (1994), a saber, que as mesmas se relacionam com o contexto histórico-socialcultural na qual se inserem e que podem, inclusive, ser usadas para a manipulação. Por todos esses fatores, atividades que abordem o Letramento Visual fazem-se necessárias e são absolutamente bem-vindas às aulas de Línguas. Ferraz (2014) oferece bons exemplos que, a meu ver, podem ser aplicados não apenas nas aulas de língua estrangeira/língua adicional, mas também nas aulas de língua materna, por exemplo atividades com filmes, clipes de seriados e documentários.

Semelhantemente ao Letramento Crítico para o qual o saber ler e escrever não são suficientes, para o Letramento Visual Crítico, não basta a habilidade de reconhecer uma imagem. Ferraz (2004) aponta que o Letramento Visual Crítico não considera a imagem apenas como uma representação da realidade, mas como um processo de significação, que se relaciona, portanto, ao seu contexto social, histórico e cultural. Embora Joly (1994) tenha uma preocupação em descrever e explicitar o poder que emana a partir da exposição a imagens e a influência das mesmas, não destaca as preocupações apontadas por Ferraz (2004), Silvino (2014), entre outros.

No tocante ao Letramento Visual, Silvino entende que:

a leitura competente de imagens nas práticas sociais (ROCHA, 2008), é a capacidade de ver, compreender e, finalmente, interpretar e comunicar o que foi interpretado através da visualização. De um modo geral, o letrado visual olha uma imagem cuidadosamente e tenta perceber as intenções da mesma. 0 
letramento visual permite que o indivíduo reúna as informações e ideias contidas em um espaço imagético colocando-as no seu contexto, determinando se são válidas ou não para a construção do seu significado. (2014, p. 168)

Silvino (ibid.), citando Procópio e Souza (2009), menciona ainda as habilidades que um indivíduo letrado visualmente deve ter, dentre elas, não apenas a compreensão dos elementos do design visual, mas também a "percepção das influências emocionais, psicológicas, fisiológicas e cognitivas apresentadas nas imagens". Assim, embora não se caracterizem visões totalmente dispares, no Letramento Crítico Visual, o conceito de imagem vai muito além daquele apresentado por Joly (1996).

Bramford (2009) afirma que o LCV envolve a habilidade necessária para que um indivíduo seja capaz de inferir significado e interpretar o conteúdo visual de uma imagem, de examinar o impacto social das mesmas e de discutir o propósito, a audiência e a propriedade de cada uma delas. Essa capacidade inclui uma análise crítica para não apenas superficialmente contemplá-las, mas crítica e internamente identificar os signos visuais e mensagens que ela comunica. O LCV também tem o propósito de fazer julgamentos da validade, precisão e valor da imagem. Hall ressalta que "signos visuais e imagens, mesmo quando eles carregam uma semelhança com as coisas a que se quer referir, são ainda signos: eles carregam significados e têm que ser interpretados" (1997, p. 19).

Dessa maneira, o LCV, assim como as outras modalidades de Letramento, merece uma atenção especial, uma vez que as manifestações visuais estão cada vez mais presentes e atuantes em nossas sociedades. Segundo CALLOW (2005), textos em linguagem não verbal, entre os quais se encontram as Imagens, formam, hoje, uma parte integrante das discussões acerca destes novos letramentos, em que as pessoas precisam ler/ver, criticar e criar uma grande variedade de itens imagéticos, desde imagens estáticas em um livro ilustrado ou em movimento no cinema e na TV (CALLOW, 2005, p. 7). Diversas investidas foram feitas com o intuito de se definir o LCV, no entanto o conceito de letramento tem alcançado proporções cada vez maiores e o entendimento acerca de suas (novas) áreas tem se expandido significativamente. Para WILEMAN (1993), o LV pode ser definido como "a habilidade de ler, interpretar e compreender informações presentes em imagens pictóricas ou gráficas" (WILEMAN, 1993, p. 114). Para Avgerinou (2009), LV diz respeito ao grupo de habilidades adquiridas, isto é, habilidades para entender (ler) e usar imagens, como também para pensar em termos de imagens.

Portanto, como podemos observar, o LV incorpora uma multiplicidade de teorias e campos de investigação, como consequência abordaremos o conceito de letramento crítico como um meio de conscientização política e mudança social a partir de uma perspectiva crítica da língua enquanto um artefato cultural que 
carrega ideologias, crenças, relações de poder e dominação (FREEBODY e LUKE, 1990; FREIRE e MACHADO, 1987; LANKSHEAR et al, 1997).

Ao analisarmos uma atividade com imagens, através das lentes do Letramento Crítico Visual, buscaremos escapar das impressões de passividade e sujeição apontadas por Joly (1994) e identificar as possibilidades de se trabalhar a criticidade dos alunos.

De acordo com Aumont (1995, p.197), "a imagem só existe para ser vista, por um espectador historicamente definido [...], e até as imagens mais automáticas [...] são produzidas de maneira deliberada, calculada, para certos efeitos sociais". A partir dessa definição, entenderemos que o texto imagético é mais e que carrega o mesmo poder de transmissão de mensagem e significado, quanto o texto escrito.

Para essa atividade buscaremos fazer uma interlocução com os 3 níveis de concepções de leitura propostos por Cassany (2006) em seu livro "Leer desde la comunidad" e os adaptaremos para a leitura de imagens.

O primeiro nível tem a ver com o a compreensão Linguística/Literal do texto escrito. Para tanto, o aluno precisará de conhecimentos prévios sobre o código, a gramática, o sistema da língua. Neste nível não se demanda inferências nem reflexão que envolva conhecimentos de mundo. Geralmente, as perguntas se referirão a informações presentes no texto, ou sobre itens lexicais ou gramaticais. Neste caso, como estamos tratando do texto imagético, entenderemos essa Compreensão como a Identificação dos componentes imagéticos explícitos e tácitos na imagem.

Em um segundo, o foco está no leitor e como o mesmo processa o texto (nesse caso, a imagem); como o mesmo recupera os implícitos; o que ele sabe e pensa sobre o que lhe é apresentado através da imagem (texto). Esse nível subjaz no entendimento Psicolinguístico ou Inferencial. Para tanto, o leitor precisa de conhecimentos prévios - conhecimento de mundo, a fim de que as inferências e formulações de hipóteses, dedução, reconhecimento de ideias, informações principais e periféricas sejam captadas para que a compreensão se dê em um nível um pouco mais aprofundado. Nesse momento, as perguntas podem motivar o uso do senso crítico, mas apenas com relação ao tema tratado no texto (na imagem), ou a uma ideia ou informação veiculadas nos mesmos. Aqui, o objetivo não é focalizar o texto como uma prática social. O que importa é que o leitor (observador) entenda o que o texto (a imagem) diz (retrata ou ilustra) sobre um determinado tema, sem considerar intenções, valores, propósitos, ideologias que estão por trás ou que podem emergir a partir da leitura do texto ou imagem.

Por fim, o terceiro nível de interpretação que consideramos perpassa o entendimento Sociocultural, ou seja, o texto (a imagem) como prática social, prática letrada. As perguntas nesse nível devem focalizar o texto como um artefato que tem uma função sociocultural na sociedade, mais especificamente, na(s) comunidades(s) em que ele circula. Esse artefato transmite informações, mas também opiniões, 
valores e ideologias (em diferentes graus, segundo os gêneros textuais). Nesse aspecto, faz-se necessário considerar nuances importantes, tais como, os enunciadores, os Interlocutores, o contexto de produção (de que lugar social, cultural, geográfico os interlocutores leem), qual a função do texto (da imagem) nesses contextos, os propósitos, as intenções, os valores, as ideologias, as relações de poder que podem ser identificados como subjacentes ao texto (a imagem). Bramford (2009) define LCV como um conjunto de habilidades necessárias para ser capaz de interpretar o conteúdo das imagens visuais, examinar impacto social das imagens e discutir o propósito, audiência e autoria. Para ele o LV também envolve o fazer julgamentos da validade e valor das imagens. Logo, hoje em dia para que um indivíduo seja um comunicador eficiente, ele precisa ter desenvolvido a habilidade de interpretação, criação e seleção de imagens para transmitir uma série de significados. Tal entendimento nos direciona a alguns pontos de convergência, entre os quais: LV é uma habilidade cognitiva, mas que se baseia no domínio afetivo; LV é descrito como habilidade e competência, envolve habilidades de compreensão e produção; por consequente, por se tratar de uma série de habilidades elas podem ser ensinadas.

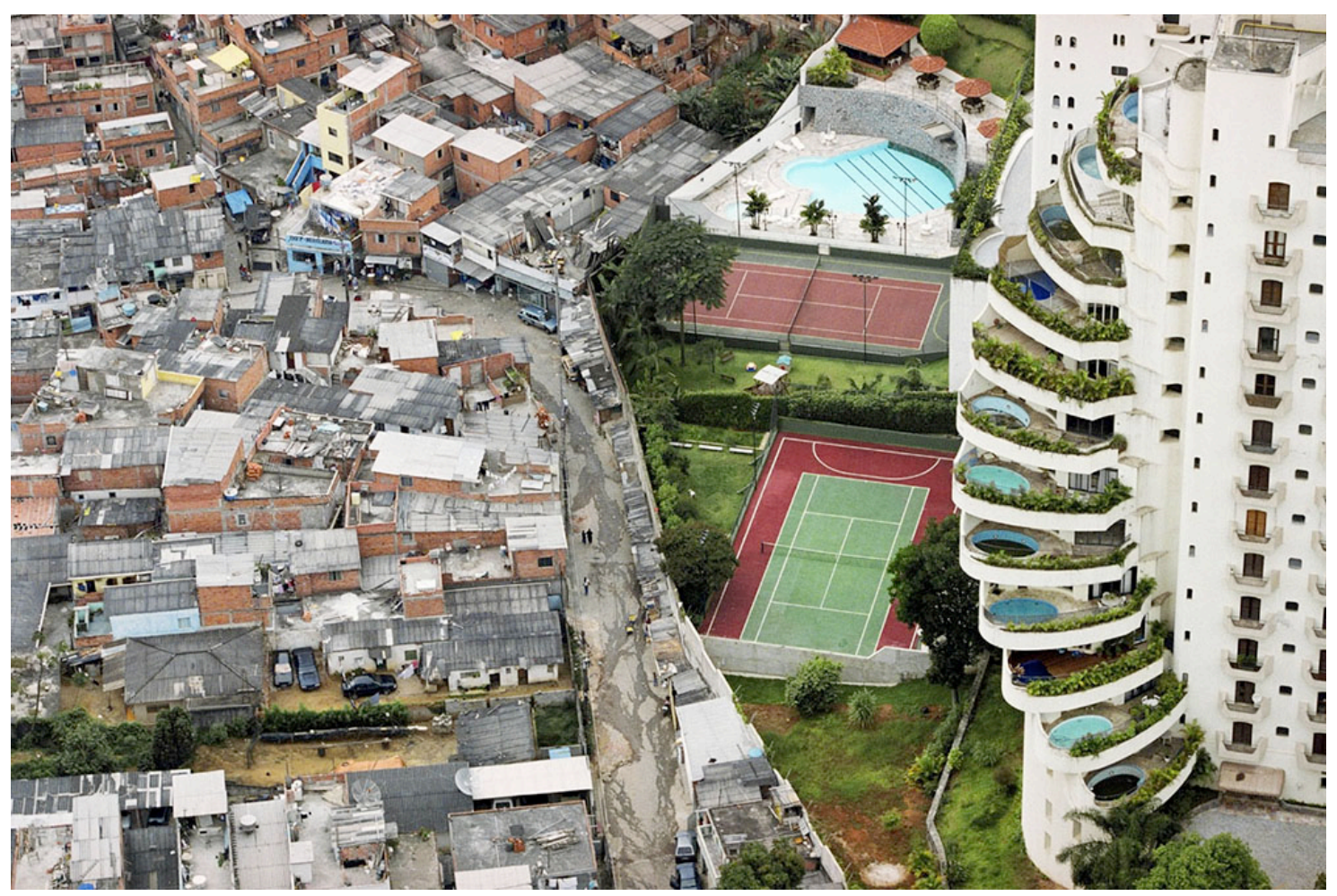

Imagem 1: Paraisópolis - São Paulo - Brasil (originalmente publicado da revista ZUM \#3, em dezembro de 2012) Foto de Tuca Vieira (Paraisópolis - SP- Brasil). 


\section{SILID IV SIMAR

\section{Contextualização}

"Recentemente, encontrei uma foto minha no Facebook, sem nenhuma menção à autoria, mas com centenas de comentários. Ninguém ali se perguntava quem fez a foto.

Pois ela foi feita há cerca de dez anos para a Folha de S. Paulo e até hoje recebo pedidos do mundo inteiro para reproduzi-la em livros, revistas e material didático. Devo muito a ela. Projetou meu trabalho, me deu prêmios, me levou a exposições aqui e no exterior. Mas o fato é que a imagem me fugiu do controle.

Em 2007, ela foi mostrada na Tate Modern, em Londres, em uma exposição chamada Cidades Globais. Era o cartaz, o convite, o fôlder, o cartão-postal e até o crachá da exposição, que incluía gente como o fotógrafo alemão Andreas Gursky. Fui convidado para a abertura, mas fiquei num hotel inferior e isolado. No dia do evento, descobri que havia um jantar de comemoração, para o qual eu não tinha sido chamado. Foi o artista turco Hüseyin Alptekin que disse: "Se o Tuca não for, eu não vou". O constrangimento foi geral.

O cara que fez a imagem emblemática da exposição não tinha o status de artista. Exibida num enorme banner no Turbine Hall, a foto possuía ali um caráter mais ilustrativo, diferente das obras de arte, imaculadas, com suas legendas e cordinhas para afastar o público. Foi quando percebi que olhavam para essa foto como se não houvesse um autor. A foto era importante, mas eu não. Comecei a ser apresentado como "Tuca, the guy who took that picture".

Não pensem que é fácil tirar uma foto como essa. Cuidei da composição, com o muro que divide os dois lados em partes iguais; cortei o céu buscando um efeito bidimensional e hipnótico. Dei vários giros com o helicóptero, orientando o piloto. Ela faz parte de uma série de fotos que fiz nessa época sobre São Paulo, e não é fruto do acaso.

Mas nada disso importa para quem a vê. E hoje essa situação já não me incomoda. Criada no ambiente do jornalismo, essa foto talvez me faça atingir o que deveria ser o grande objetivo de um artista: provocar uma reflexão sobre o mundo e não sobre a obra e seu autor. Talvez esse seja o grande mérito da foto. Ela se libertou do autor e do contexto original para enriquecer um debate sobre o Brasil, sobre a América Latina, sobre a desigualdade. Para um filho de socialista, criado num ambiente de indignação e desejo de transformação social, nada poderia ser mais gratificante. Jornalismo, arte e política aqui são indissociáveis.

E veja que, a rigor, a-foto-da-favela-de-Paraisópolis (isso soa como um mantra incessante, um verso alexandrino em busca de uma rima que lhe dê repouso) não mostra exatamente como são as coisas. Nesse prédio com as piscinas não estão os mais ricos, que, por sua vez, não moram colados aos mais pobres, que, por sua vez, não são os moradores de Paraisópolis. O poder simbólico e didático da imagem prevalece, com sua gramática visual simples e direta. Há quem diga que é Photoshop, o que parece mais uma descrença no que a cena mostra do 
que na foto em si. O absurdo da imagem nos impõe uma sensação de derrota inaceitável: como deixamos que as coisas chegassem a esse ponto?

Às vezes essa foto me enche o saco. Tenho projetos novos para mostrar mas a cena de Paraisópolis com frequência ofusca outros trabalhos. Para alguém jovem como eu, é difícil falar em legado. Mas é um tema que me vem involuntariamente quando surge essa foto. Será que é isso que quero deixar para o futuro? Será que tudo mais que eu fizer nunca vai ter a importância dessa única foto?

Li outro dia que nos últimos quatro anos foram feitas mais fotografias do que em todo o resto da história da fotografia. Pensando bem, talvez não seja tão mau ter pelo menos uma que importa". (originalmente publicado da revista ZUM \#3, em dezembro de 2012) Disponível em: http://www.tucavieira.com.br/A-foto-da-favelade-Paraisopolis.

Como podemos ler, a foto 'Paraisópolis' ganhou repercurssão internacional. A imagem acima encabeçou a reportagem chamada - Three Billion Careful Owners do Jornal Britânico The Guardian em 17 de Junho de 2007. A reportagem fazia menção ao crescimento exponencial das cidades como consequência da vinda de imigrantes e migrantes para as grandes metrópoles em busca de melhores condições de vida. Ainda, a reportagem ressaltava que embora, idealística e confortavelmente, não haja espaço para todos, os seres humanos se adaptam e conseguem encontrar maneiras de sobreviverem em meio a -segundo a reportagem- catastrófica, contudo maravilhosa cidade grande.

\section{Atividade}

1) O que pode ser observado na Imagem ?

2) O que mais chama a sua atenção na Imagem?

3) Você já esteve em algum lugar semelhante aos lugares mostrados na Figura?

4) Como é o Estilo de vida de quem mora lá?

5) E no outro lugar você já esteve?

6) Qual sentimento, na sua opinião, a situação retrada na Imagem gera nas pessoas que ali vivem?

7) Qual sentimento a situação retratada gera em você?

8) Após a observação da Imagem aponte as diferenças entre o estilo de vida das pessoas que moram nesses dois contextos. Como ambos se diferenciam?

9) Para você, essa situação é comum onde você vive? O que gera a situação retratada na Imagem?

10) Você acredita que essa situação pode ser de alguma forma mudada? Se sim, como?

11) Se não, por que não?

12) Escolha uma palavra ou pequena frase que descreva cada um dos contextos observados na Imagem. E justifique a sua escolha.

13) Para você, o que o fotografo estava tentando retratar ao tirar essa foto? 
14) A partir da análise da Imagem qual ideia se forma no seu imaginário acerca de quem são os moradores desses lugares, como se comportam?

15) Imagine que você tivesse a chance de encontrar com esses moradores de Paraisópolis, o que você os perguntaria?

16) O que significa para você as palavras "casa" e "lar". Há alguma diferença?

17) Sabendo que a Imagem acima foi exibida em uma galeria de arte em Londres Inglaterra, o que você imagina que os estrangeiros que ainda não conhecem o Brasil podem inferir ou captar a partir dela.

18) Qual legenda você colocaria nessa Imagem?

\section{Análise}

Ao revisitar esse arcabouço teórico, busquei elucidar como as perguntas propostas na atividade se fazem necessárias para a relevância e efetividade em fomentar e estimular no leitor da imagem Paraisópolis, um senso de liberdade para lê-la e interpretá-la sensata e criticamente.

Ao propor a pergunta número 1 objetivei levar o aluno a descrever de forma literal o tudo que estava exposto explicitamente na imagem, sem ater-se a nenhuma outra nuance especifica. Para tanto, o aluno não precisaria de muitos recursos, apenas a fotografia e sua observação.

Ao propor as perguntas de número: 2 - 11 objetivei levar o aluno a formular hipóteses sobre o tema abordado pela imagem: diferença social, desigualdades sociais, dualidade entre riqueza/pobreza, luxo/condições precárias e compartilhar o que mais lhe chamou a atenção na mensagem passada pela imagem.

Ao propor as perguntas número: 12, 13, 14, 15, 16 e 17, objetivei traçar um paralelo explicito entre o texto imagético e a realidade do aluno, levando-o a considerar o possível meio no qual esse texto imagético circula, o contexto de produção e recepção do mesmo, assim como, as suas significações, intenções e impacto sobre aqueles que se submeterem à sua análise.

\section{Referências Bibliográficas}

AVGERINOU, M., \& ERICSON, J. (1997). A review of the concept of Visual Literacy. British Journal of Educational Technology, 28(4), 280-291.

BARTHES, Roland. O terceiro sentido. In.: 0 óbvio e o obtuso: ensaios críticos III. Trad. Léa Novaes. Rio de Janeiro: Nova Fronteira, 1990. p. 45-61.

BRAMFORD, A. (2009) The visual literacy white paper. Disponível em: http://www.adobe.com/uk/education/pdf/adobe_visual_literacy_paper.pdf 
BRASIL. Orientações Curriculares para o Ensino Médio: linguagens, códigos e suas tecnologias. 2006. Acesso em: 20 ago. 2014. Disponível em: http://www.letras.ufmg.br/profs/reinildes/dados/arquivos/ocem.pdf.

CALLOW, J. Literacy and the visual: Broadening our vision. English teaching: Practice and Critique, vol. 4, n. 1, 2005.

CASSANY, D. Tras las líneas. Sobre la lectura contemporánea. Barcelona: Editorial Anagrama, 2006.

DUBOC, A. P. \& FERRAZ, D. M. Letramentos Críticos e Formação de Professores de Inglês: Currículos e Perspectivas em Expansão. In: Letramentos e Multiletramentos no Ensino de Línguas e Literaturas. Revista X, vol.1, 2011.

FERRAZ, D. M. Palestra: Educação Crítica. 2014. Acesso em: 19 ag. 2014. Disponível em: https://www.youtube.com/watch?v=Fz5pId1DZjQ.

- Visual Literacy: the interpretation of images in English classes Revista Eventos Pedagógicos v.5, n.1 (10. ed.), número especial, p. 16 - 28, jan./maio, 2014

GEE, J. P. (1997). Meanings in discourse: Coordinating and being coordinated in Muspratt, S., Luke, A. \& Freebody, P (Eds.), Constructing Critical Literacies. Cresskill, New Jersey: Hampton Press.

HALL, Joan; An, Cheng; Carlson, Matthew (2006). Reconceptualizing multicompetence as a theory of language knowledge. Applied Linguistics

HALL, S. (1997). The work of representation. In S. Hall (Ed.), Representation: Cultural Representations and Signifying Practices (pp. 13-75). Bonhill Street, London: Sage Publication Ltd.

HARMER, J. The practice of English language teaching. Third Edition. Essex: Longman, 2003.

HAWKINS, M. R. (ed.) Social justice language teacher education. Toronto: Multilingual Matters, 2011. 178p.

HOLDEN, S.; ROGERS, M. 0 ensino da língua inglesa. 2 ed. São Paulo: SBS Editora, 2002.

JOLY, M. Introdução à análise da imagem. Campinas: Papirus, 1996. 
KUMARADIVELU, B. Individual identity, cultural globalization and teaching English as an international language: The case for an epistemic break. In: ALSAGOFF, L., RENANDYA, W.; HU, Guangwei; MCKAY, S. (eds.). Teaching English as an International Language: Principles and Practices (pp. 9-27). New York: Routledge, 2012.

. (2006). TESOL methods: Changing tracks, challenging trends.

TESOL Quarterly, 40(1), 59-81.

LANKSHEAR, C.; KNOBEL, M. New Literacies: Changing Knowledge and Classroom Research. Buckingham: Open University Press, 2007a.

linguistics'. Australian Review of Applied Linguistics 33 (2), 16.1-16.16. DOI: 10.2104/aral1016.

LARAIA, R. B. Cultura: Um Conceito Antropológico. Rio de Janeiro: Jorge Zahar Editor, 7a edição, 1993.

LUKE, A. \& FREEBODY, P.(1997). Critical literacy and the question of normativity: An introduction in Muspratt, S., Luke, A. \& Freebody, P (Eds.), Constructing Critical Literacies. Cresskill, New Jersey: Hampton Press.

MATTOS, A. M. A. Novos letramentos, ensino de língua estrangeira e o papel da escola pública no século XXI. 2011. Acesso em: 19 de junho de 2013. Disponível em: http://ojs.c3sl.ufpr.br/ojs2/index.php/revistax/article/viewFile/ $22474 / 16915$.

MENEZES DE SOUZA, L.M. Global Learning in the Knowledge Society: four tools for discussion. In: Zeitschrift für internationale Bildungsforschung und Entwicklungspädagogik, v. 31, Nuermberg, Alemanha, 2008.

MENEZES DE SOUZA, L.M. Post-Colonial Literature and a Pedagogy of Re-Visioning: the contribution of Wilson Harris. In: Claritas. São Paulo, 1994.

MONTE MÓR, W. 2006. Reading Dogville in Brazil: Image, Language and Critical Literacy, Language and Intercultural Communication. London: Multilingual Matters.

. 2007. Investigating Critical Literacy at the University in Brazil, Critical

Literacy. Menezes de Souza, L.M. T. \& Andreotti, V. (eds) www.criticalliteracy.org.uk

Caderno de Orientações Didáticas para EJA - Inglês. São Paulo:

Secretaria Municipal de Educação, 2010. Disponível em 
<http://portalsme.prefeitura.sp.gov.br/Projetos/BibliPed/Documentos/publicacoes/o rienta_ing_portal.pdf > Acesso 15 Abril 2011.

- Critical literacies, meaning making and new epistemological perspectives. Rev. Eletrónica Matices en Lenguas Extranjeiras, no. 2, 2008.

.; MENEZES DE SOUZA, L. M. Formação de professores nas teorias dos novos letramentos e multiletramentos: o ensino crítico de línguas estrangeiras na escola. Projeto Nacional (núcleo sede). São Paulo: USP, 2009.

Critical Literacies, Meaning making and new epistemological perspectives. 2008. Acesso em: 04 set. 2014. Disponível em: http://www.revistamatices.unal.edu.co/pdfs/05walkyria.pdf

Palestra: Letramento Crítico: Visões de crítica. 2014. FALE: UFMG.

MORIN, E. Ciência com Consciência. Rio de Janeiro: Bertrand Brasil, 1998.

O Método 5: A humanidade da humanidade. A identidade humana. Trad. Juremir Machado da Silva. 2a edição. Porto Alegre : Sulina, 2003.

PENNYCOOK, A. Critical and Alternative Directions in Applied Linguistics. Australian Review of Applied Linguistics. v. 33, n. 2, 2010.

PROCÓPIO, E. O livro na era digital: o mercado editorial e as mídias digitais. São Paulo: Giz, 2010.

SILVINO, Flávia Felipe. Letramento Visual. Texto Livre, v. 7, n. 1, 2014, p. 167170.

SOARES, M. Letramento: um tema em três gêneros. Belo Horizonte: Autêntica, 1998.

SOUZA, P. Os recursos visuais no ensino-aprendizagem de vocabulário em língua estrangeira. Maringá, v. 31, n. 2, p. 139-146, 2009.

TORTATO, C. O livro didático de inglês: uma análise das diretrizes curriculares de língua estrangeira moderna do Estado do Paraná - Curitiba, 2010.

WILEMAN, R. E. Visual communicating. Englewood Cliffs, N.J.: Educational Technology Publications, 1993. 